\title{
Modulating the vascular behavior of metastatic breast cancer cells by curcumin treatment
}

\section{Anna L. Palange 1,2,3, Daniele Di Mascolo1,2,3, Jaykrishna Singh ${ }^{1,2}$, Maria S. De Franceschi ${ }^{3}$, Claudio Carallo ${ }^{3}$, Agostino Gnasso ${ }^{3}$ and Paolo Decuzzi ${ }^{1,2,3 *}$}

1 Department of Translational Imaging, The Methodist Hospital Research Institute, Houston, TX, USA

${ }^{2}$ Department of Nanomedicine, The Methodist Hospital Research Institute, Houston, TX, USA

${ }^{3}$ Department of Experimental and Clinical Medicine, University of Magna Graecia, Catanzaro, Italy

\section{Edited by:}

Michael R. King, Cornell University, USA

\section{Reviewed by:}

Hao Xu, University of Texas Southwestern Medical Center, USA Jocelyn Marshall, Cornell University, USA

\section{${ }^{*}$ Correspondence:}

Paolo Decuzzi, Department of Translational Imaging, The Methodist Hospital Research Institute, Houston, TX 77030, USA.

e-mail:pdecuzzi@tmhs.org
The spreading of tumor cells to secondary sites (tumor metastasis) is a complex process that involves multiple, sequential steps. Vascular adhesion and extravasation of circulating tumor cells (CTCs) is one, critical step. Curcumin, a natural compound extracted from Curcuma longa, is known to have anti-tumoral, anti-proliferative, anti-inflammatory properties and affect the expression of cell adhesion molecules, mostly by targeting the NF-kB transcription factor. Here, upon treatment with curcumin, the vascular behavior of three different estrogen receptor negative $\left(\mathrm{ER}^{-}\right)$breast adenocarcinoma cell lines (SK-BR3, MDA-MB-231, MDA-MB-468) is analyzed using a microfluidic system. First, the dose response to curcumin is characterized at 24,48 , and $72 \mathrm{~h}$ using a XTT assay. For all three cell lines, an $\mathrm{IC}_{50}$ larger than $20 \mu \mathrm{M}$ is observed at $72 \mathrm{~h}$; whereas no significant reduction in cell viability is detected for curcumin concentrations up to $10 \mu \mathrm{M}$. Upon $24 \mathrm{~h}$ treatment at $10 \mu \mathrm{M}$ of curcumin, SK-BR3 and MDA-MB-231 cells show a decrease in adhesion propensity of $40 \%(p=0.02)$ and $47 \%(p=0.001)$, respectively. No significant change is documented for the less metastatic MDA-MB-468 cells. All three treated cell lines show a $20 \%$ increase in rolling velocity from 48.3 to $58.7 \mu \mathrm{m} / \mathrm{s}$ in SK-BR-3, from 64.1 to $73.77 \mu \mathrm{m} / \mathrm{s}$ in MDA-MB-231, and from 57.5 to $74.4 \mu \mathrm{m} / \mathrm{s}$ in MDA-MB-468. Collectively, these results suggest that mild curcumin treatments could limit the metastatic potential of these adenocarcinoma cell lines, possibly by altering the expression of adhesion molecules, and the organization and stiffness of the cell cytoskeleton. Future studies will elucidate the biophysical mechanisms regulating this curcumin-induced behavior and further explore the clinical relevance of these findings.

Keywords: circulating tumor cells, vascular adhesion, parallel plate flow chamber, curcumin treatment, metastasis

\section{INTRODUCTION}

The spreading of primary tumors to secondary sites (tumor metastasis) is responsible for a dramatic decrease in survival rate, with about $90 \%$ of the deaths in cancer patients being related to metastasis (Wittekind and Neid, 2005). Although, for a long time, this has been considered as a late stage process in tumor growth, recently it has been realized that metastatic niches can form and progress almost simultaneously with the primary mass (Klein, 2009). Metastasis is a multi-step process where tumor cells have to overcome several barriers before growing at secondary sites: (i) invade the normal tissue surrounding the tumor mass; (ii) enter the bloodstream; (iii) survive in the circulatory system; (iv) leave the blood stream and infiltrate the normal tissue; and (v) proliferate there, evading the immune system surveillance (Morris et al., 1997; Fidler, 2003; Chaffer and Weinberg, 2011). Each of these steps represents an impediment to the distant spreading of the disease that only a few primary tumor cells (one CTC out of a billion of blood cells) can overcome. Yet, metastasis occurs very often in cancer patients (Wong et al., 2001; Chambers et al., 2002).

A critical step in this process is the vascular transport of tumor cells in the hostile hemodynamic environment and the extravasation to secondary sites (Wyckoff et al., 2000). Circulating tumor cells (CTCs), transported by the blood flow, are subjected to mechanical stress, generated by high shear forces and collisions with other cells; and immunological stress, as these cells can be recognized and attacked by lymphocytes (Al-Mehdi et al., 2000; Chang et al., 2008; Vivier et al., 2008). Extravasation and infiltration are generally associated with pro-metastasis modifications of the CTCs (i.e., epithelial-mesenchymal transition) that originate in the primary mass and continue in the circulation (Iwatsuki et al., 2010; Labelle et al., 2011). The actual mechanism for extravasation depends on the tumor type and metastatic environment and can involve the (i) geometrical trapping of CTCs in narrow blood vessels (diameter $<40 \mu \mathrm{m}$ ); (ii) adhesion to endothelial cells, in a leukocyte-like fashion, mediated or not mediated by platelets; and (iii) a combination of these mechanisms (Ribatti et al., 2006; Miles et al., 2008).

In this study, the main focus is on the vascular adhesion of CTCs under flow, as schematically shown in Figure 1. This process consists of two sequential steps: (i) CTC rolling over the vascular walls, regulated by the engagement of endothelial E-selectin and P-selectin with tumor cell glycoprotein such as CD44, CEA, CD24, sulfate glycosaminoglycans (CS-GAGs), sialylated glycosphingolipids; (ii) CTC firm arrest, regulated by other 


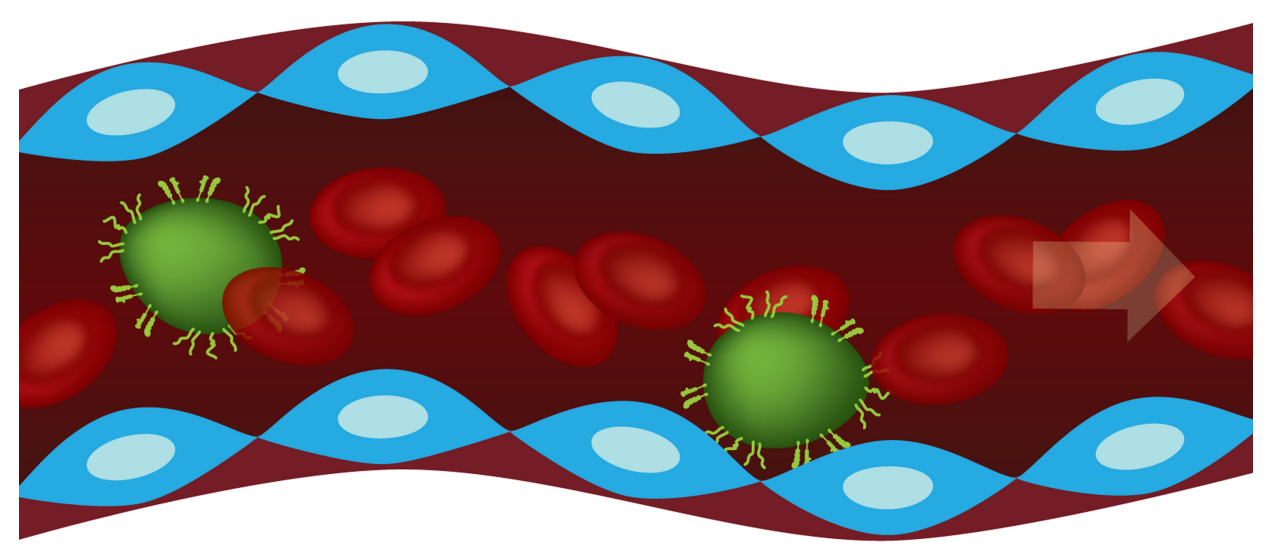

FIGURE 1 | Schematic representation of circulating tumor cells (CTCs in green) transported by the blood flow and tethering the endothelial cells (blue) through ligand molecules.

endothelial receptors (ICAM-1, VCAM-1), and different families of integrin molecules $\left(\alpha_{v} \beta_{3}, \beta_{2}\right.$ integrins; Wirtz et al., 2011; Geng et al., 2012). In organs with high occurrence of metastasis, such as the liver, this picture is even more complicated in that the characteristic discontinuous and fenestrated endothelium leaves the underlying extracellular matrix directly accessible to CTCs. Moreover, vascular adhesion is also supported by the reorganization and deformation under flow of the cell cytoskeleton. Although tumor cells do not exhibit a leukocyte-like cortical cytoskeleton which is capable of extensive and rapid deformation, it is possible that CTCs exposed to shear stresses in the circulation could undergo transformations facilitating attachment to the vessel walls (Davies et al., 2005). Indeed, firm arrest is a necessary condition for the subsequent extravasation and colonization of the surrounding tissue.

The development of therapeutic agents against metastatic disease is still in its infancy, due to a lack in understanding the leading pathways and, most importantly, their alterations in secondary tumor cells. Also, most of the efforts have been traditionally oriented to eradicate tumor cells already proliferating at the secondary sites, neglecting the opportunity of blocking or modulating one or multiple steps in the metastatic cascade (Chambers et al., 2000). Novel micro- and nanotechnologies detecting, capturing, and characterizing CTCs are providing new and more accurate information on the biomechanical properties of malignant cells in the circulation. Microfluidic systems used as diagnostic tools are demonstrating the significant correlation between higher CTC counts in blood and lower patient survival (Cristofanilli et al., 2004; King et al., 2009; Han et al., 2010; Hughes and King, 2012). It is then reasonable to speculate that novel therapies, possibly nanoparticle-based, could open new avenues for an effective treatment of metastatic diseases by eradicating, or dramatically lowering, the number of CTCs.

In this work, the effect of curcumin on the rolling and adhesion mechanics under flow of three estrogen receptor $\left(\mathrm{ER}^{-}\right)$breast adenocarcinoma cell lines, namely SK-BR-3, MDA-MB-231, and MDA-MB-468, is analyzed. These cell lines were chosen for their different metastatic potential. Curcumin is a natural multi-target compound with anti-tumoral and anti-inflammatory properties (Kumar et al., 1998; Ray et al., 2003; Kunnumakkara et al., 2008; Binion et al., 2009; Yodkeeree et al., 2010). Their rolling velocity and adhesion propensity are measured experimentally upon treatment with curcumin, using a parallel plate flow chamber system.

\section{MATERIALS AND METHODS \\ MATERIALS AND CHEMICALS}

SK-BR-3, MDA-MB-231, MDA-MB-468 breast adenocarcinoma cells were obtained from the American Type Cell Culture Collection (ATCC) and cultured in the recommended medium. SK-BR-3 were grown at $37^{\circ} \mathrm{C}$, under a humidified $5 \% \mathrm{CO}_{2}$ and $95 \%$ air at one atmosphere, MDA-MB-231 and MDA-MB-468 were grown at $37^{\circ} \mathrm{C}$ in a free gas exchange with atmospheric air. Collagen type I from calf skin was obtained from Sigma Aldrich (St. Louis, MO, USA). Curcumin (diferuloylmethane) and dimethyl sulfoxide (DMSO) were obtained from Fisher Scientific. XTT kit was obtained from Trevigen (Gaithersburg, Maryland).

\section{CYTOTOXIC EFFECT OF CURCUMIN AND XTT ASSAYS}

Curcumin was first dissolved in DMSO as a $10 \mathrm{mM}$ stock solution and subsequently diluted in cell culture medium. Medium containing the same amount of DMSO was used as control at concentrations not exceeding the $0.1 \% \mathrm{v} / \mathrm{v}$ of the culture medium. Cells were incubated with curcumin at $1,10,20$, and $40 \mu \mathrm{M}$, at three time points namely 24,48 , and $72 \mathrm{~h}$. Cell proliferation was measured with conventional XTT reduction assays. Briefly, SKBR-3, MDA-MB-231, and MDA-MB-468 cells were inoculated at a density of $5 \times 10^{3}$ cells in 96 -well plates for $24 \mathrm{~h}$ in $200 \mu \mathrm{l}$ of recommended medium. The culture supernatant was then removed and medium containing the above mentioned curcumin concentrations was added to cells, subsequently incubated for 24,48 , and $72 \mathrm{~h}$. After that, XTT-dye was mixed with phenol-free medium and added to the samples. The plate was incubated for at least $1 \mathrm{~h}$ before reading. The absorbance of XTT-formazan dye was then measured using a microplate reader at $490 \mathrm{~nm}$. Twenty-five repetitions were performed for each time point and concentration. 


\section{PARALLEL PLATE FLOW CHAMBER FOR CELL ROLLING AND ADHESION}

Before flow adhesion experiments, cells were first incubated with medium containing no FBS for $7 \mathrm{~h}$ and then treated with or without curcumin at $10 \mu \mathrm{M}$ for $24 \mathrm{~h}$. Subsequently, cells were detached from culture dishes by mild trypsinization ( $0.25 \%$ trypsin/EDTA) for $2 \mathrm{~min}$ at $37^{\circ} \mathrm{C}$ and incubated at $37^{\circ} \mathrm{C}$ for $1 \mathrm{~h}$ to allow the regeneration of surface glycoproteins. After that, cells were washed in PBS and resuspended at $10^{6}$ cells $/ \mathrm{ml}$ in serum-free medium containing $0.1 \%$ bovine serum albumin, following standard protocols (McCarty et al., 2000).

The rolling and adhesion behavior of the tumor cells, was studied using a parallel plate flow chamber system (Chen et al., 1997; Brown and Larson, 2001; GlycoTech Corporation; Figure 2). The system comprises a commercially available flow chamber, a syringe pump (Harvard Apparatus, MA), an inverted epifluorescent microscope (Nikon Ti-Eclipse) and a desktop computer for data storage and analysis. The main constituents of the flow chamber are a deck, a rubber gasket and a glass slide. The rubber gasket defines the geometry of the flow region (length $l=20 \mathrm{~mm}$; width $b=10 \mathrm{~mm}$; height $h=0.254 \mathrm{~mm}$ ). The coverslips (slide), closing the bottom of the chamber, were covered with a uniform collagen layer. In particular, autoclaved $35 \mathrm{~mm}$ coverslips were covered by a collagen solution obtained diluting collagen type I from calf skin (Sigma Aldrich) in PBS to reach a concentration of about $50 \mathrm{mg} / \mathrm{cm}^{2}$. After about $5 \mathrm{~h}$ at room temperature, the cover slips were rinsed in PBS and left under the bio-hood to dry. To perfuse the solution at a fixed wall shear rate $S$, flow rate $Q$ is finely controlled through the syringe pump given that $S=6 Q / b h^{2}$.

After assembling all the components, the system was placed on the stage of an epifluorescent microscope (Nikon Ti-Eclipse). The Andor's Luca EM S camera utilizes a $658 \times 496$ "interline frame transfer" EMCCD sensor to acquire the region of interest (ROI) and allows for real time monitoring. For each experiment $10^{6} / \mathrm{ml}$ cells were perfused in $1 \mathrm{ml}$ of serum-free medium, at a wall shear rate of $S=10 \mathrm{~s}^{-1}$ (mimicking the circulation environment of microvascular tumor vessels). Eight experiments were performed for the SK-BR-3 and MDA-MB-468-treated and untreated cells, and 10 experiments for the MDA-MB-231. All the experiments lasted 12 min each.

Through offline data analysis on the movies derived from each experiment, the number of firmly adhering cells on the substrate and their mean rolling velocity were quantified. Firmly adhering cells were those cells staying within the region of interest $(10 \times$ objective, ROI $=658 \times 496$ pixel) till the end of the experiment. This number was normalized by the total number of injected cells and the area of the ROI $\left(\sim 0.33 \times 10^{-6} \mathrm{~m}^{2}\right)$ deriving the adhesion propensity. The rolling velocity was calculated as the displacement of the centroid of the cells divided by the time interval of their observation (on average about $10 \mathrm{~s}$ ). The rolling velocity was calculated for 12 cells in three different SK-BR-3 experiments $(n=36)$, and six cells in eight different MDA-MB-231 and MDAMB-468 experiments $(n=48)$, for both the treated and the control group.

\section{STATISTICAL ANALYSIS}

Data are expressed as means $\pm \mathrm{SD}$. Statistical significance of differences between means was determined by one-way ANOVA. Probability values of $p<0.05$ were considered statistically significant.

\section{RESULTS AND DISCUSSION}

The cytotoxic effect of curcumin on SK-BR-3, MDA-MB-231, and MDA-MB-468 cells was analyzed using a XTT proliferation assay. Cells were incubated with curcumin at different doses, namely $1,10,20$, and $40 \mu \mathrm{M}$, and for three time points, namely 24,48 ,

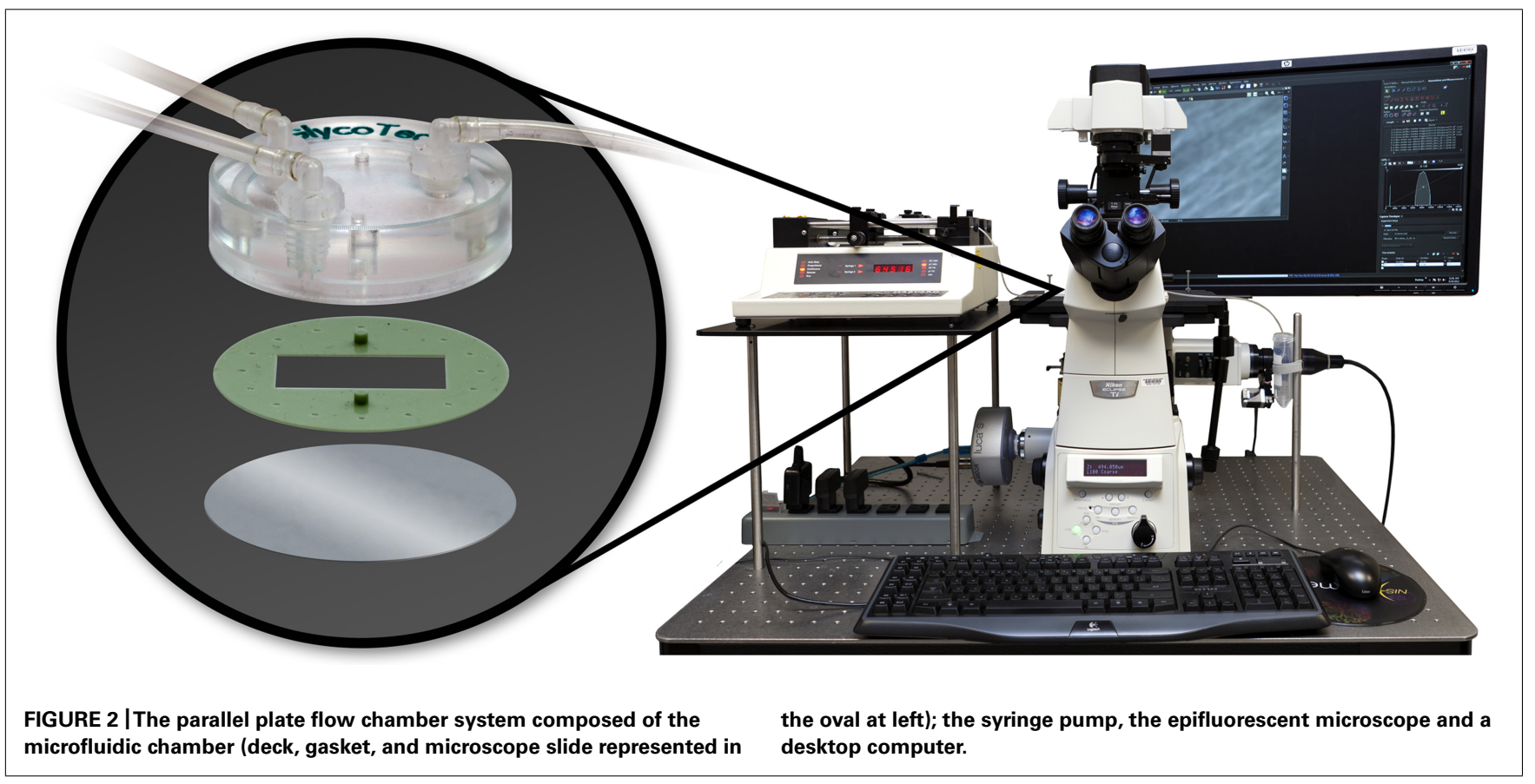


and $72 \mathrm{~h}$. The cell viability was measured following the protocols described in Section "Materials and Methods" and is reported in the bar charts of Figure 3, for 25 repetitions in each cell line. As expected the percentage of viable cells reduces as the concentration and the duration of the treatment increase. Interestingly, for concentrations lower and equal to $10 \mu \mathrm{M}$, curcumin has no significant effect on the cell viability. Note that for the control experiments, cell culture medium was added with the same amount of DMSO used in the actual experiments for dissolving curcumin. This volume was about $0.1 \%$ of the total medium volume and no sign of toxicity was observed on the cells. For larger concentrations, 20 and $40 \mu \mathrm{M}$, the curcumin treatment limits cell proliferation in a dose and time dependent manner. Cell viabilities lower than $50 \%$ can only be observed at the highest concentration and longer time points $\left(48\right.$ and $72 \mathrm{~h}$ ). The $\mathrm{IC}_{50}$ is reached at $\sim 20 \mu \mathrm{M}$ for the SK-BR-3 and MDA-MB-468 at $72 \mathrm{~h}$; and at $\sim 40 \mu \mathrm{M}$ for the MDA-MB-231 at $72 \mathrm{~h}$. This is in agreement with most literature on curcumin (Aoki et al., 2007). From this assay, the exposure to $10 \mu \mathrm{M}$ of curcumin for $24 \mathrm{~h}$ was considered a mild treatment inducing no significant, direct effects on cell viability.

The effect of curcumin on the rolling and adhesion behavior of the three breast adenocarcinoma cells lines SK-BR-3, MDA-MB231, and MDA-MB-468 was analyzed using a parallel plate flow chamber, traditionally employed for the analysis of leucocyte adhesion and rolling (Lawrence et al., 1987). The cells, mildly pretreated with curcumin $(24 \mathrm{~h}$ at $10 \mu \mathrm{M})$ as detailed in Section "Materials and Methods," were infused in the apparatus depicted in Figure 2 and their rolling velocity and firm adhesion was quantified via post processing of the images taken with an epifluorescent microscope. The bar charts of Figure 4 present the results of the flow chamber assay. Figure 4A shows the adhesion propensity of the curcumin-treated cells (Curc-treated) and untreated cells (Ctr), as the ratio between the absolute number of adhering cells $\left(n_{\mathrm{adh}}\right)$, the total number of injected cells $\left(n_{\text {inj }}=10^{6}\right)$, and the area of the region of interest $\left(A=0.33 \times 10^{-6} \mathrm{~m}^{2}\right)$. SK-BR-3, MDA-MB-231, and MDA-MB-468-treated cells present an adhesion propensity of $90.7 \pm 29.2,58.58 \pm 19.70$, and $132.97 \pm 31.34 \# / \mathrm{m}^{2}$, respectively. This means that for a vessel of $50 \mu \mathrm{m}$ in diameter with a $500 \mu \mathrm{m}$ length (vascular area $\sim 1 \mathrm{~mm}^{2}$ ), about 300 SK-BR-3, 180 MDAMB-231, and 400 MDA-MB-468 cells would firmly adhere under the same biophysical conditions and assuming that $10^{6} \mathrm{CTC}$ enter the specific vessel. On the other hand, the untreated cells exhibit a larger adhesion propensity of $151.1 \pm 60.84,109.69 \pm 38.19$, and $155.42 \pm 20.74 \# / \mathrm{m}^{2}$, for the SK-BR-3, MDA-MB-231, and MDA$\mathrm{MB}-468$, respectively. The difference between the two populations (Curc-treated and Ctr) is significant for the SK-BR-3 and even more for the highly metastatic MDA-MB-231 cells. More specifically, the curcumin-treated SK-BR-3 cells show a $40 \%$ decrease $(p=0.02)$ in adhesion and the curcumin-treated MDA-MD231 a $47 \%$ decrease $(p=0.001)$ as compared to the control group. Conversely, the difference in adhesion propensity between curcumin-treated MDA-MB-468 cells and the control group is not statistically significant $(p=0.099)$.

Rolling velocity is reported in Figure 4B. This physical quantity was estimated as the ratio between the displacement of the cell centroid over the corresponding observation time. Despite the large standard deviation, this analysis shows that there is a significant difference between the two groups (Curc-treated and Ctr) in all three cell lines: SK-BR-3 and MDA-MB-231-treated tumor cells roll $\sim 1.2$ times faster than the control cells $(p=0.01, p=0.009$, respectively), MDA-MB-468-treated tumor cells rolls $\sim 1.3$ times faster than the control cells $(p=0.00005)$. In particular, the rolling velocities are $58.66 \pm 20.29$ and $48.33 \pm 11.3 \mu \mathrm{m} / \mathrm{s}$ for SK-BR3 -treated and untreated cells, $73.77 \pm 21.21$ and $64.1 \pm 12.89$ for MDA-MB-231-treated and untreated cells, $74.38 \pm 24.88$ and $57.49 \pm 11.96$ for MDA-MB-468-treated and untreated cells, respectively. Indeed, the higher rolling velocity correlates well with the lower adhesion propensity observed above.

These preliminary results collectively would suggest that mild treatments with curcumin could impair cell adhesion and increase cell rolling under flow over normal, untreated cells. Indeed, this could reduce the metastatic potential of CTCs. Understanding the mechanisms regulating the observed alteration in the behavior of SK-BR-3, MDA-MB-231, and MDA-MB-468 cells is out of the scope of this preliminary study. However, it has already been reported that curcumin treatments alter the organization of microfilaments and increase the overall quantity of F-actin. This would affect cell motility and deformability, which are crucial elements in supporting tumor cell circulation and survival in the blood stream. Moreover, recently it has been shown that CTCs reattach in distant tissues by a mechanism that is tubulin-dependent and suppressed by polymerized actin (Holy, 2004; Matrone et al., 2010). In addition, curcumin is known to decrease the expression and
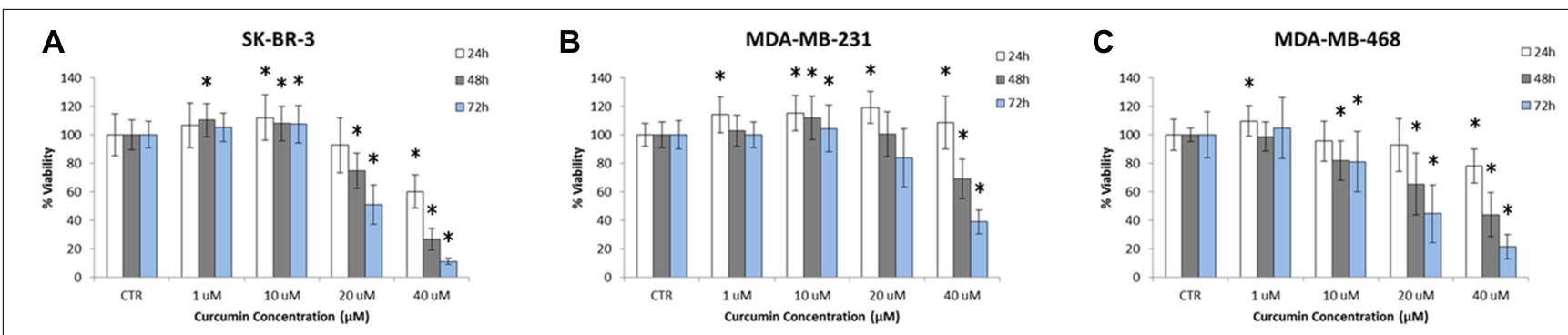

FIGURE 3 | Proliferation of (A) SK-BR-3, (B) MDA-MB-231, (C) MDA-MB468 cells exposed to different concentrations of curcumin $(1,10,20$, and $40 \mu \mathrm{M})$ at three time points $(\mathbf{2 4}, \mathbf{4 8}$, and $\mathbf{7 2} \mathrm{h})$. Note that cell proliferation is not affected at curcumin concentrations below $10 \mu \mathrm{M}$ up to $72 \mathrm{~h}(n=25)$. The asterisk symbol "*" denotes significant difference $(p<0.05)$ as compared to control (Ctr) 

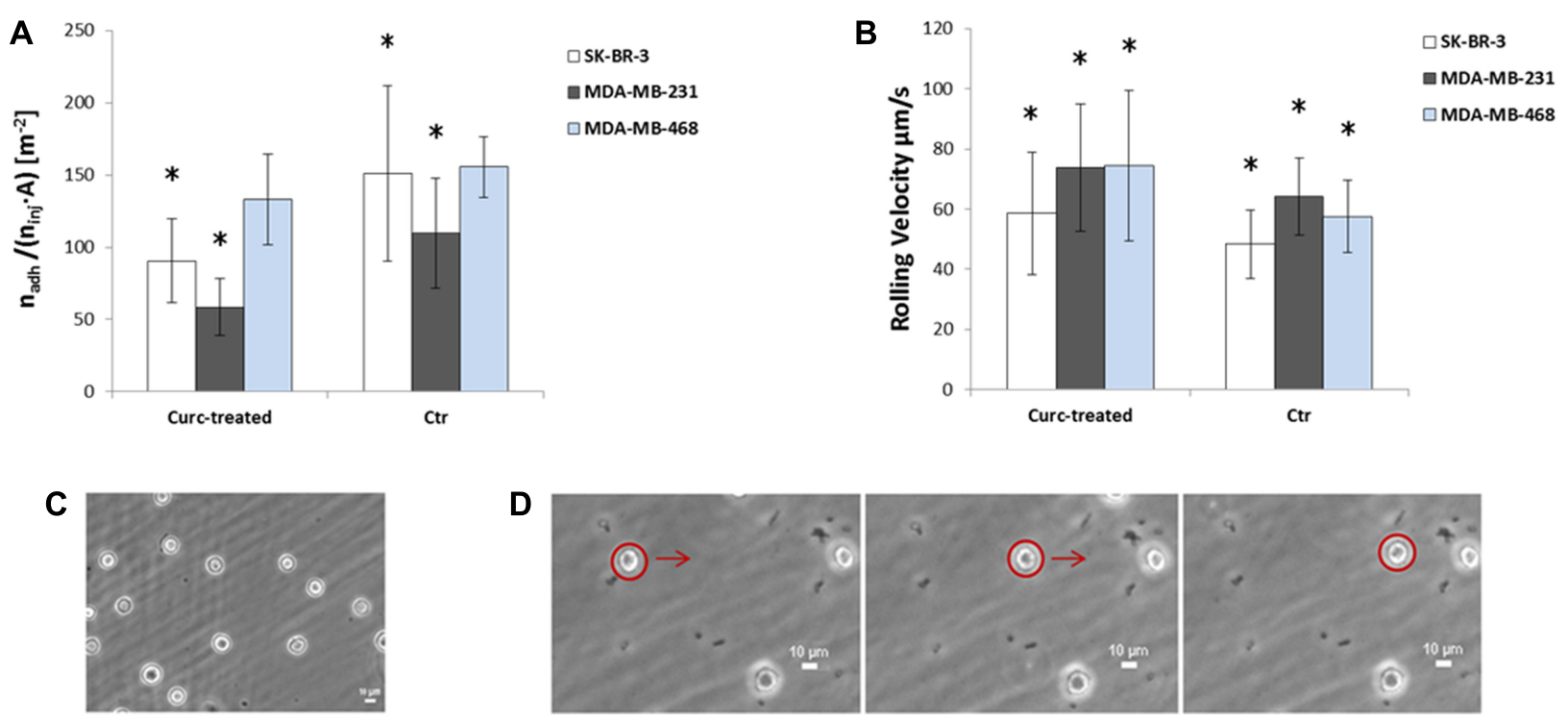

FIGURE 4 | (A) Adhesion and (B) rolling behavior of SK-BR-3 (white), MDA-MB-231 (gray), MDA-MB-468 (blue) cells treated with curcumin (Curc-treated) at $10 \mu \mathrm{M}$ for $24 \mathrm{~h}$, and not treated cells (Ctr). The number of firmly adhering cells $\left(n_{\text {adh }}\right)$ is normalized by the total number of injected cells $\left(n_{\text {inj }}=10^{6}\right)$ and the area of the region of interest $\left(A=0.33 \times 10^{-6} \mathrm{~m}^{2}\right)$. Data are plotted as mean \pm SD. The asterisk symbol "* " denotes significant difference ( $p<0.05$ ) as compared to control (Ctr). (C) Image of firmly adhering SK-BR3 cells on the substrate at the end of the experiment. (D) Captured frames showing the displacement of a rolling cell on the substrate. modulate the activity of membrane adhesion molecules by acting on the transcription factor NF- $\kappa$ B. For instance, the curcumin inhibition of NF- $\kappa \mathrm{B}$ completely blocked TNF- $\alpha$ induced expression of adhesion molecules (ICAM-1, VCAM-1, and E-selectin) on HUVECs and human intestinal microvascular endothelial cells attenuating leucocytes adhesion (Kumar et al., 1998; Ray et al., 2003; Binion et al., 2009). Therefore, in the present case, it is reasonable to speculate that curcumin effects could depend, at least in part, on a reduced expression or more likely, on the modulation of integrins receptor activity (mostly $\alpha_{1} \beta_{1}$ and $\alpha_{2} \beta_{1}$ ) thus limiting the adhesion propensity under flow (Park et al., 2006; Ivascu and Kubbies, 2007). Here, it is important to note that integrins, expressed on cellular membrane, can specifically bind to the collagen type I, deposited on the flow chamber glass slide. Also, in organs with high metastatic occurrence, such as the liver, the discontinuous, fenestrated endothelium allows the CTCs to directly interact and bind to ECM components. For this reason, collagen type I, has been also used in flow chamber experiments to assess the adhesive behavior of cells and CTCs (Haier et al., 1999; Wendel et al., 2012).

Finally, curcumin, a natural compound extracted from Curcuma longa, has been demonstrated to have a wide spectrum of biological and pharmacological activities. In particular, it exhibits antiviral, antibacterial, antioxidant, anti-inflammatory, anti-proliferative, and anti-angiogenic properties (Aggarwal et al., 2003; Holt etal., 2005). Animal and human studies have suggested its potential use in the treatment of inflammation and cancer, mostly because of its potent effect on the NF- $\kappa$ B pathway (Kawamori et al., 1999; Aggarwal, 2004). However, the major drawback in its clinical use is the very low bioavailability and biodistribution, mostly due to its poor absorption from the gut, rapid metabolism and elimination (Shoba et al., 1998; Anand et al., 2007). The formulation of curcumin into nanoparticles could avoid the drawbacks listed above and enhance its curative properties.

\section{CONCLUSION}

The ER negative breast metastatic cells, SK-BR-3, MDA-MB231, and MDA-MB-468, cells were treated with curcumin, at three different time points. For sufficiently large curcumin doses $(\geq 20 \mu \mathrm{M})$, significant cell death is induced at $72 \mathrm{~h}$. Conversely, a mild treatment with curcumin $(\leq 10 \mu \mathrm{M}$ at $24 \mathrm{~h})$, did not show any significant change in cell viability but did affect the vascular behavior of the cells. This was demonstrated by assessing the cell adhesion and rolling velocity in a parallel plate flow chamber system. The SK-BR-3 cells showed a $40 \%$ decrease $(p=0.02)$ in cell adhesion propensity and $20 \%$ increase $(p=0.001)$ in rolling velocity. The MDA-MB-231-treated cells showed almost a 50\% decrease $(p=0.001)$ in cell adhesion propensity and about $15 \%$ increase $(p=0.009)$ in rolling velocity. The MDA-MB-468-treated cells did not show any statistically significant decrease in adhesion propensity, but did roll 1.3 times faster than the control group $(p=0.00005)$.

Collectively, these results suggest that mild curcumin treatments of CTCs could lower or even prevent the occurrence of metastasis, by reducing CTCs adhesion at secondary vascular sites. Future works will have to elucidate the mechanisms regulating the observed alteration in tumor cell behavior and the specific pathways involved in each cell line studied, by characterizing the expression and activity of cell membrane receptors, the organization of the cell cytoskeleton and its deformability. However, the proper delivery of sufficient doses of curcumin 
to CTCs could provide a new strategy to prevent the metastatic spread.

\section{ACKNOWLEDGMENTS}

This work was partially supported by the Cancer Prevention Research Institute of Texas through the grant CPRIT RP110262; the National Institutes of Health (NIH, USA) through the grants U54CA143837 and U54CA151668. Anna L. Palange and Daniele

\section{REFERENCES}

Aggarwal, B. B. (2004). Nuclear factor$\kappa \mathrm{B}$ : the enemy within. Cancer Cell 6, 203-208.

Aggarwal, B. B., Kumar, A., and Bharti, A. C. (2003). Anticancer potential of curcumin: preclinical and clinical studies. Anticancer Res. 23, 363-398.

Al-Mehdi, A. B., Tozawa, K., Fisher, A. B., Shientag, L., Lee, A., and Muschel, R. J. (2000). Intravascular origin of metastasis from the proliferation of endothelium-attached tumor cells: a new model for metastasis. Nat Med. 6, 100-102.

Anand, P., Kunnumakkara, A. B., Newman, R. A., and Aggarwal, B. B. (2007). Bioavailability of curcumin: problems and promises. Mol. Pharm. 4, 807-818.

Aoki, H., Takada, Y., Kondo, S., Sawaya, R., Aggarwal, B. B., and Kondo, Y. (2007). Evidence that curcumin suppresses the growth of malignant gliomas in vitro and in vivo through induction of autophagy: role of Akt and extracellular signalregulated kinase signaling pathways. Mol. Pharmacol. 72, 29-39.

Binion, D. G., Heidemann, J., Li, M. S., Nelson, V. M., Otterson, M. F., and Rafiee, P. (2009). Vascular cell adhesion molecule-1 expression in human intestinal microvascular endothelial cells is regulated by PI 3-kinase/Akt/MAPK/NF-kappaB: inhibitory role of curcumin. Am. J. Physiol. Gastrointest. Liver Physiol. 297, G259-G268.

Brown, D. C., and Larson, R. S. (2001). Improvements to parallel plate flow chambers to reduce reagent and cellular requirements. BMC Immunol. 2, 9. doi: 10.1186/1471-2172-2-9

Chaffer, C. L., and Weinberg, R. A. (2011). A perspective on cancer cell metastasis. Science331, 1559-1564.

Chambers, A. F., Groom, A. C., and MacDonald, I. C. (2002). Dissemination and growth of cancer cells in metastatic sites. Nat. Rev. Cancer 2, 563-572.

Chambers, A. F., MacDonald, I. C., Schmidt, E. E., Morris, V. L., and Groom, A. C. (2000). Clinical targets for anti-metastasis therapy. $A d v$. Cancer Res. 79, 91-121.
Chang, S. F., Chang, C. A., Lee, D. Y., Lee, P. L., Yeh, Y. M., Yeh, C. R., et al. (2008). Tumor cell cycle arrest induced by shear stress: roles of integrins and Smad. Proc. Natl. Acad. Sci. U.S. A. 105, 3927-3932.

Chen, S., Alon, R., Fuhlbrigge, R. C., and Springer, T. A. (1997). Rolling and transient tethering of leukocytes on antibodies reveal specializations of selectins. Proc. Natl. Acad. Sci. U.S.A. 94, 3172-3177.

Cristofanilli, M., Budd, G. T., Ellis, M. J., Stopeck, A., Matera, J., Miller, M. C., et al. (2004). Circulating tumor cells, disease progression, and survival in metastatic breast cancer. N. Engl. J. Med. 351, 781-791.

Davies, P. F., Spaan, J. A., and Krams, R. (2005). Shear stress biology of the endothelium. Ann. Biomed. Eng. 33, 1714-1718.

Fidler, I. J. (2003). The pathogenesis of cancer metastasis: the "seed and soil" hypothesis revisited. Nat. Rev. Cancer 3, 453-458.

Geng, Y., Marshall, J. R., and King, M. R. (2012). Glycomechanics of the metastatic cascade: tumor cellendothelial cell interactions in the circulation. Ann. Biomed. Eng. 40, 790-805.

Haier, J., Marwan, Y. N., and Nicolson, G. L. (1999). $\beta 1$-integrin-mediated dynamic adhesion of colon carcinoma cells to extracellular matrix under laminar flow. Clin. Exp. Metastasis 17, 377-387.

Han, W., Allio, B. A., Foster, D. G., and King, M. R. (2010). Nanoparticle coatings for enhanced capture of flowing cells in microtubes. ACS Nano 4, 174-180.

Holt, P. R., Katz, S., and Kirshoff, R. (2005). Curcumin therapy in inflammatory bowel disease: a pilot study. Dig. Dis. Sci 50, 2191-2193.

Holy, J. (2004). Curcumin inhibits cell motility and alters microfilament organization and function in prostate cancer cells. Cell Motil. Cytoskeleton 58, 253-268.

Hughes, A. D., and King, M. R. (2012). Nanobiotechnology for the capture and manipulation of circulating tumor cells. Wiley Interdiscip. Rev. Nanomed. Nanobiotechnol. 4, 291-309.

Di Mascolo acknowledge the Doctoral School of The University of Magna Graecia (Italy) for travel support. Daniele Di Mascolo also acknowledges the support of the EU Commission, the European Social Fund and the department 11 "Culture - Education - University - Research - Technological Innovation - Higher Education" of Calabria Region (POR Calabria FSE 2007/2013). The authors wish to thank Mr. Matthew Landry at TMHRI for his help with the artwork.

Ivascu, A., and Kubbies, M. (2007). Diversity of cell-mediated adhesions in breast cancer spheroids. Int. J. Oncol. 31, 1403-1413.

Iwatsuki, M., Mimori, K., Yokobori, T., Ishi, H., Beppu, T., Nakamori, S., et al. (2010). Epithelial-mesenchymal transition in cancer development and its clinical significance. Cancer Sci. 101, 293-299.

Kawamori, T., Lubet, R., Steele, V. E., Kelloff, G. J., Kaskey, R. B., Rao, C. V., et al. (1999). Chemopreventive effect of curcumin, a naturally occurring anti-inflammatory agent, during the promotion/progression stages of colon cancer. Cancer Res. 59, 597-601.

King, M. R., Western, L. T., Rana, K., and Liesveld, J. L. (2009). Biomolecular surfaces for the capture and reprogramming of circulating tumor cells. J. Bionic Eng. 6, 311-317.

Klein, C. A. (2009). Parallel progression of primary tumor and metastasis. Nat. Rev. Cancer 9, 302-312.

Kumar, A., Dhawan, S., Hardegen, N. J., and Aggarwal, B. B. (1998). Curcumin (Diferuloylmethane) inhibition of tumor necrosis factor (TNF)-mediated adhesion of monocytes to endothelial cells by suppression of cell surface expression of adhesion molecules and of nuclear factor-kappaB activation. Biochem. Pharmacol. 55, 775-783.

Kunnumakkara, A. B., Anand, P., and Aggarwal, B. B. (2008). Curcumin inhibits proliferation, invasion, angiogenesis and metastasis of different cancers through interaction with multiple cell signaling proteins. Cancer Lett. 269, 199-225.

Labelle, M., Begum, S., and Hynes, R. O. (2011). Direct signaling between platelets and cancer cells induces an epithelial-mesenchymal-like transition and promotes metastasis. Cancer Cell 120, 576-590.

Lawrence, M. B., McIntire, L. V., and Eskin, S. G. (1987). Effect of flow on polymorphonuclear leukocyte/endothelial cell adhesion. Blood 70, 1284-1290.

Matrone, M. A., Whipple, R. A., and Balzer, E. M. and Martin, S. S. (2010). Microtentacles tip the balance of cytoskeletal forces in circulating tumor cells. Cancer Res. 70, 7737-7741.

McCarty, O. J. T., Mousa, S. A., Bray, P. F., and Konstantopoulos, K. (2000). Immobilized platelets support human colon carcinoma cell tethering, rolling, and firm adhesion under dynamic flow conditions. Blood 96, 1789-1797.

Miles, F. L., Pruitt, F. L., Van Golen, K. L., and Cooper, C. R. (2008). Stepping out of the flow: capillary extravasation in cancer metastasis. Clin. Exp. Metastasis 25, 305-324.

Morris, V. L., Schmidt, E. E., Mac Donald, I. C., Groom, A. C., and Chambers, A. F. (1997). Sequential steps in hematogenous metastasis of cancer cells studied by in vivo videomicroscopy. Invasion Metastasis 17, 281-296.

Park, C. C., Zhang, H., Pallavicini, M., Gray, J. W., Baehner, W., Park, C. J., et al. (2006). $\beta 1$ integrin inhibitory antibody induces apoptosis of breast cancer cells, inhibits growth, and distinguishes malignant from normal phenotype in three dimensional cultures and in vivo. Cancer Res. 66, 1526-1535.

Ray, S., Chattopadhyay, N., Mitra, A., Siddiqi, M., and Chatterjee, A. (2003). Curcumin exhibits antimetastatic properties by modulating integrin receptors, collagenase activity, and expression of $\mathrm{Nm} 23$ and E-cadherin. J. Environ. Pathol. Toxicol. Oncol. 22, 49-58.

Ribatti, D., Mangialardi, G., and Vacca, A. (2006). Stephen Paget and the "seed and soil" theory of metastatic dissemination. Clin. Exp. Med. 6, 145-149.

Shoba, G., Joy, D., Joseph, T., Majeed, M., Rajendran, R., and Srinivas, P. S. (1998). Influence of piperine on the pharmacokinetics of curcumin in animals and human volunteers. Planta Med. 64, 353-356.

Vivier, E., Tomasello, E., Baratin, M., Walzer, T., and Ugolini, S. (2008). Functions of natural killer cells. Nat Immunol. 9, 503-510.

Wendel, C., Hemping-Bovenkerk, A., Krasnyanska, J., Torge Mees, S., 
Kochetkova, M., Stoeppeler, S., et al. (2012). CXCR4/CXCL12 participate in extravasation of metastasizing breast cancer cells within the liver in a rat model. PLOS ONE 7, e30046. doi: 10.1371/journal.pone. 0030046

Wirtz, D., Konstantopoulos, K., and Searson, P. C. (2011). The physics of cancer: the role of physical interactions and mechanical forces in metastasis. Nat. Rev. Cancer 11, 512-522.

Wittekind, C., and Neid, M. (2005). Cancer invasion and metastasis. Oncology 69(Suppl. 1), 14-16.
Wong, C. W., Lee, A., Shientag, L., Yu, J., Dong, Y., Kao, G., et al. (2001). Apoptosis: an early event in metastatic inefficiency. Cancer Res. 61, 333-338. Wyckoff, J. B., Jones, J. G., Condeelis, J. S., and Segall, J. E. (2000). A critical step in metastasis: in vivo analysis of intravasation at the primary tumor. Cancer Res. 60, 2504-2511.

Yodkeeree, S., Ampasavate, C., Sung, B., Aggarwal, B. B., and Limtrakul, P. (2010). Demethoxycurcumin suppresses migration and invasion of MDA-MB-231 human breast cancer cell line. Eur. J. Pharmacol. 627, 8-15.
Conflict of Interest Statement: The authors declare that the research was conducted in the absence of any commercial or financial relationships that could be construed as a potential conflict of interest.

Received: 03 July 2012; accepted: 23 October 2012; published online: 15 November 2012.

Citation: Palange AL, Di Mascolo D, Singh J, De Franceschi MS, Carallo C Gnasso A and Decuzzi P (2012) Modulating the vascular behavior of metastatic breast cancer cells by curcumin treatment.
Front. Oncol. 2:161. doi: 10.3389/fonc. 2012.00161

This article was submitted to Frontiers in Cancer Molecular Targets and Therapeutics, a specialty of Frontiers in Oncology. Copyright (c) 2012 Palange, Di Mascolo, Singh, De Franceschi, Carallo, Gnasso and Decuzzi. This is an openaccess article distributed under the terms of the Creative Commons Attribution License, which permits use, distribution and reproduction in other forums, provided the original authors and source are credited and subject to any copyright notices concerning any third-party graphics etc. 